Shinji Komori • Hiroshi Kato • Shin-ichiro Kobayashi

Koji Koyama • Shinzo Isojima

\title{
Transmission of $\mathbf{Y}$ chromosomal microdeletions from father to son through intracytoplasmic sperm injection
}

Received: January 11, 2002 / Accepted: May 19, 2002

\begin{abstract}
We conducted chromosomal analysis of three male infants fathered by severe oligozoospermic males with $\mathrm{Y}$ chromosomal microdeletions through intracytoplasmic sperm injection (ICSI). Two of the infants had the same Y chromosomal microdeletions as their fathers. The third infant also had a Y chromosomal microdeletion, which was longer than that found in his father. The results confirm that $Y$ chromosomal microdeletions are transmitted from a father to a son via ICSI and also suggest that the microdeletions may be expanded during such transmission. Genetic counseling for infertile couples contemplating ICSI is important if the male carries $\mathrm{Y}$ chromosomal microdeletions.
\end{abstract}

Key words Microdeletion $\cdot \mathrm{Y}$ chromosome $\cdot$ Azoospermia Oligozoospermia $\cdot$ ICSI

\section{Introduction}

Infertility is a major problem affecting $10 \%-15 \%$ of couples seeking to have children, and a male factor can be identified in one third of these couples. Spermatogenic failure has been shown to be a major cause of male infertility (Thielemans et al. 1998).

Evidence exists that microdeletions in three regions of the $\mathrm{Y}$ chromosome, azoospermic factor (AZF)a, AZFb, and $\mathrm{AZFc}$, play an important role in spermatogenesis and male infertility (Vogt et al. 1996), although the identity and

S. Komori $(\bowtie) \cdot$ K. Koyama

Department of Obstetrics and Gynecology, Hyogo College of

Medicine, 1-1 Mukogawa-cho, Nishinomiya, Hyogo 663-8131, Japan

Tel. +81-798-45-6481; Fax +81-798-46-4163

e-mail: komor615@hyo-med.ac.jp

S. Komori · K. Koyama

Laboratory of Developmental Biology and Reproduction, Institute for Advanced Medical Sciences, Hyogo, Japan

H. Kato $\cdot$ S. Kobayashi $\cdot$ S. Isojima

Advanced Fertility Center, Huchu Hospital, Osaka, Japan function of the genes involved are not clear at present (Ma et al. 1993; Reijo et al. 1995; McElreavey and Krausz 1999; Foresta et al. 2001; Stouffs et al. 2001). Foresta et al. (2001) reported that $402(8.2 \%)$ of 4868 infertile men examined from 1992 to 2000, including $10.5 \%$ of azoospermic and severe oligo-zoospermic men (sperm count $<5 \times 10^{6} / \mathrm{ml}$ ) and $3.8 \%$ of intracytoplasmic sperm injection (ICSI) candidates, carried Y chromosomal microdeletions. Our studies have indicated that $7.6 \%$ of Japanese azoospermic and severe oligozoospermic men (sperm count $<1 \times 10^{6} / \mathrm{ml}$ ) have microdeletions in the AZFc region of the $\mathrm{Y}$ chromosome (Kato et al. 2001). Others have also reported microdeletions of the Y chromosome in azoospermic and oligozoospermic males (Kobayashi et al. 1994; Simoni et al. 1997; Pryor et al. 1997; Kostiner et al. 1998; Vogt 1998; McElreavey and Krausz 1999; Simoni 2001; Kleiman et al. 2001).

With the advancement of assisted reproductive technology (ART), an increasing number of infertile couples have been able to have babies (Palermo et al. 1992; Van Steirteghem et al. 1993). In the case of male infertility caused by severe oligozoospermia, ICSI has been successfully used to fertilize the egg. However, this method may allow direct transmission of some genetic defects from father to son (Pryor et al. 1997; Vogt 1998; Thielemans et al. 1998). Several researchers have reported that male offspring born through ICSI carry the same microdeletions of the Y chromosome as their fathers (Jiang et al. 1999; Kamischke et al. 1999; Page et al. 1999).

In this study, we analyzed microdeletions in three male infants fathered by means of ICSI in Japanese infertile males with microdeletions. We report that the same or similar microdeletions were identified in all of these male offspring.

\section{Subjects and methods}

ICSI was performed using sperm from three oligozoospermic men with Y chromosomal microdeletions (Fig. 1). Their wives became pregnant and delivered male infants. 
Fig. 1a-c. Analysis of Y chromosomal microdeletions in infertile men and their male offspring who were fathered using intracytoplasmic sperm injection. $P$, Positive control (normal male sample); $F$, father; $S$, son; $M$, molecular marker (Hae III digest of f174 DNA). Solid bars indicate regions without microdeletions. a case 1 . b case 2 . c case 3 a
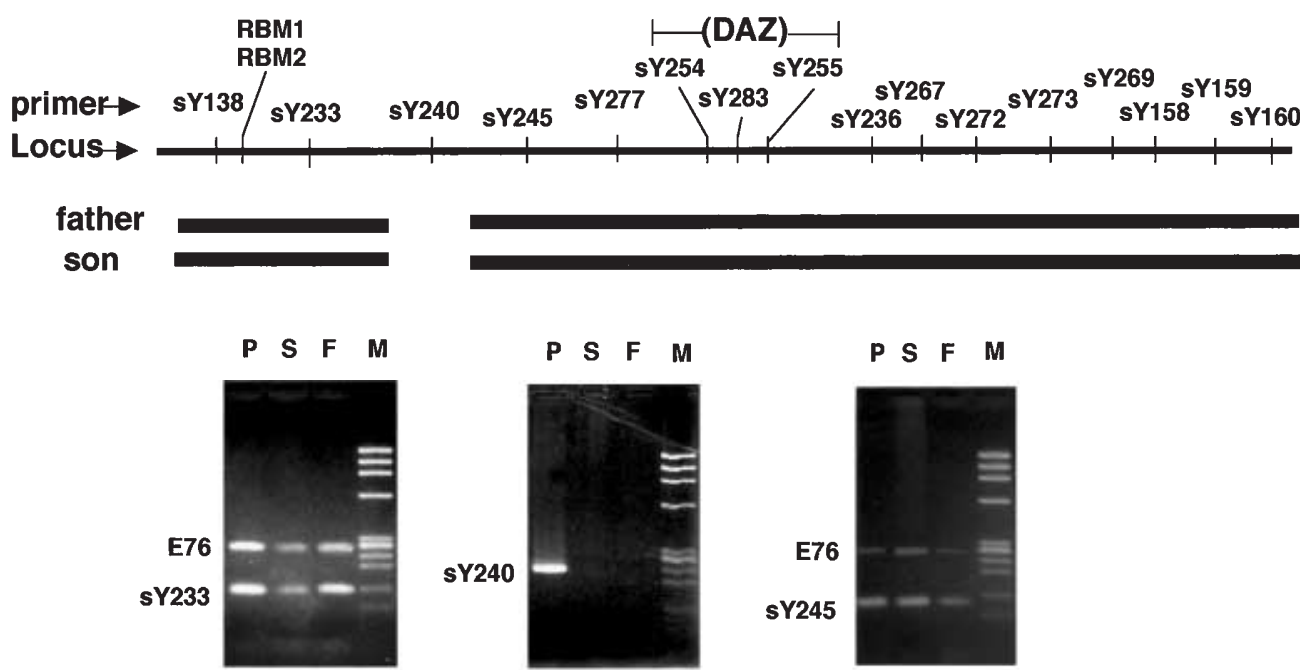

P S F M

P S F M
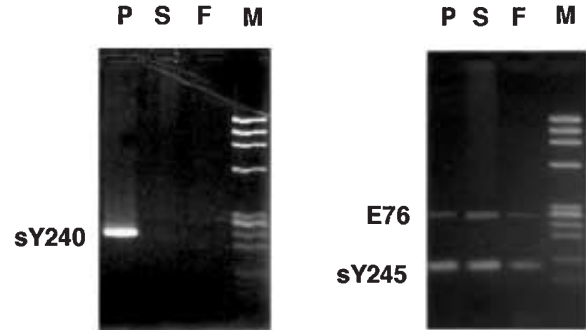

b
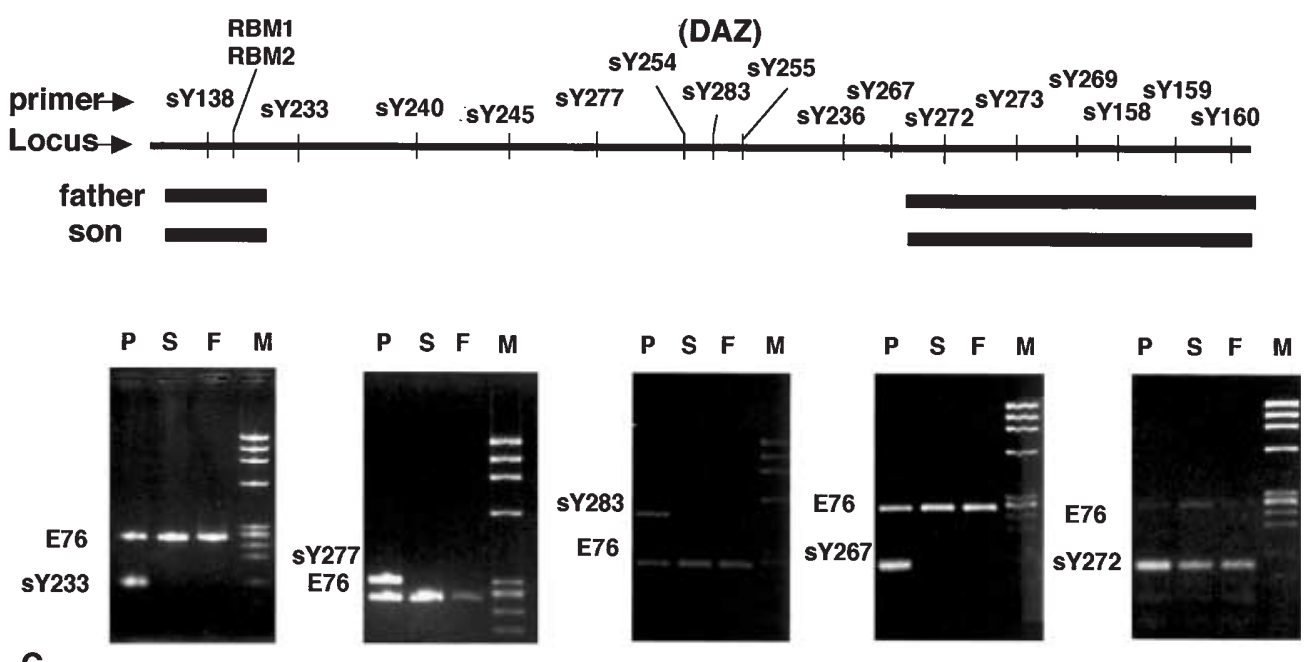

C
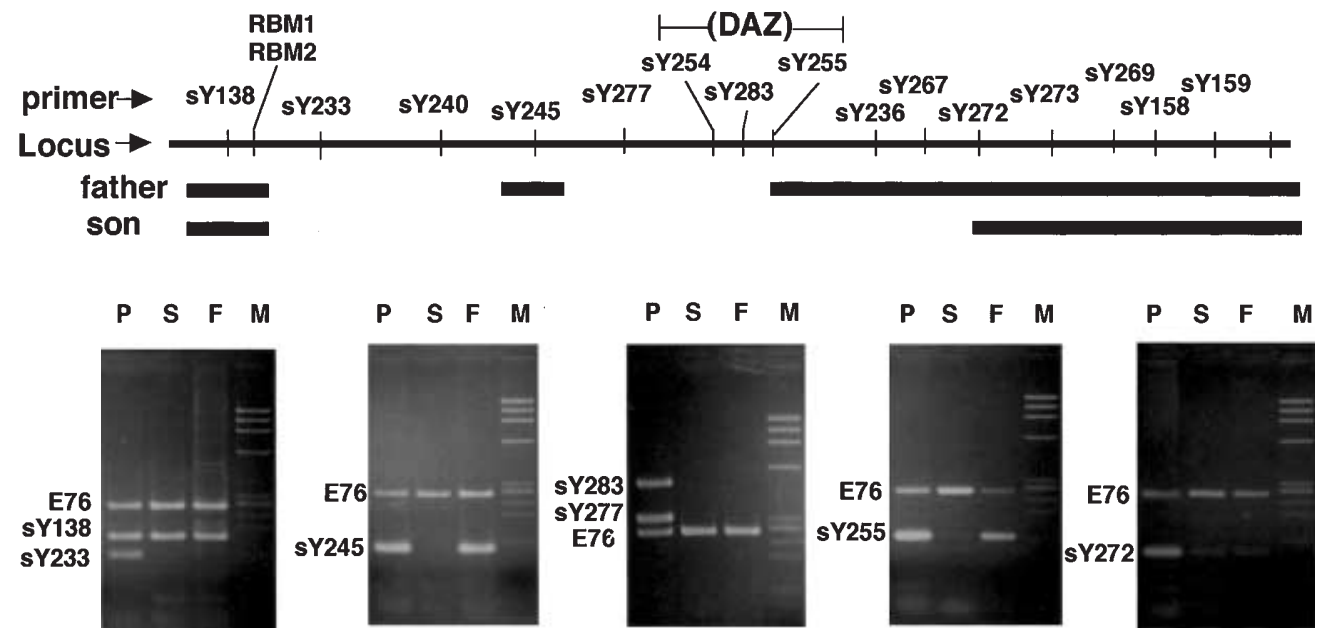

After informed consent was obtained, umbilical cord blood (cases 1 and 2) or peripheral blood (case 3) was analyzed for Y chromosomal microdeletions. DNA was extracted from the blood samples and digested with EcoR I, which allowed the polymerase chain reaction (PCR) to proceed smoothly. PCR was performed using 16 sets of primers located in the interval D16-22 of the Y chromosome (sY138, sY233, sY240, sY245, sY277, sY254, sY283, sY255, sY236, sY267, 
sY272, sY269, sY273, sY158, sY159, and sY160 (Vollrath et al. 1992), as described previously (Kato et al. 2001). E76 primer (ACACAGAGCAAGGCCA GAAT) and E77 primer (CTTCATGGGCCTGAACT GAT) (Ma et al. 1993) were used as positive controls. Genomic DNA was dissolved in PCR buffer $(50 \mathrm{mmol} / 1 \mathrm{KCl}, 15 \mathrm{mmol} / \mathrm{l}$ $\mathrm{MgCl}_{2}, 0.1 \%$ gelatin, $10 \mathrm{mmol} / 1$ Tris $\mathrm{HCl}$ at $\left.\mathrm{pH} 8.3\right)$ and mixed with $20 \mathrm{mmol} / 1$ deoxyribonucleoside triphosphate (deoxyadenosine triphosphate, deoxythymidine triphosphate, deoxyguanosine triphosphate, deoxycytidine triphosphate), $1 \mathrm{mmol} / 1$ primer, and 1.87 units of Thermus aquaticus DNA polymerase (Applied Biosystems Division, Foster City, CA, USA). After preheating at $95^{\circ} \mathrm{C}$ for $5 \mathrm{~min}$, PCR was performed by denaturing at $95^{\circ} \mathrm{C}$ for $1 \mathrm{~min}$, annealing at $57^{\circ} \mathrm{C}$ for $2 \mathrm{~min}$ and ending with a primer extension at $72^{\circ} \mathrm{C}$ for $3 \mathrm{~min}$ in 35 cycles. The reaction mixture was then incubated at $72^{\circ} \mathrm{C}$ for $5 \mathrm{~min}$. The products were analyzed by gel electrophoresis in $2 \%$ NuSieve GTG agarose (FMC BioProducts, Rockland, ME, USA) and 1\% Seakem GTG agarose (FMC BioProducts) in Tris-acetate-EDTA buffer $(40 \mathrm{mmol} / 1$ Tris-acetate, $1 \mathrm{mmol} / 1$ ethylenediamine tetraacetic acid).

\section{Results}

In case 1, PCR analysis detected a microdeletion in the Y chromosome that was the same as that found in his father's DNA (Fig. 1a). Case 2 also showed the same deletion in the Y chromosome as that of his father (Fig. 1b). Case 3 had a larger deletion in the $\mathrm{Y}$ chromosome than that of his father (Fig. 1c).

\section{Discussion}

Recent studies of mechanisms of infertility have identified some genetic disorders associated with spermatogenic defects in infertile males (Thielemans et al. 1998). In particular, close relationships between microdeletions in the $\mathrm{Y}$ chromosome and spermatogenic failure have been reported (Pryor et al. 1997; Kostiner et al. 1998; Vogt 1998; McElreavey and Krausz 1999; Foresta et al. 2001; Kato et al. 2001; Kleiman et al. 2001; Simoni 2001). About 10\% of infertile males with azoospermia and oligozoospermia have Y chromosomal microdeletions around the AZF region. For males who are infertile because of severe spermatogenic defects, such as azoospermia and severe oligozoospermia with Y chromosomal microdeletions, ART such as ICSI is often used successfully to achieve fertilization (Kostiner et al. 1998; Vogt 1998; Foresta et al. 2001). However, since ICSI is the direct introduction of a spermatozoon into an oocyte, bypassing the induction of capacitation and acrosome reaction by a motile spermatozoon for oocyte penetration, the possibility exists that ICSI may transmit genetic abnormalities from a father to a son (Kretser and Baker 1999; Foresta et al. 2001).
In this study, we showed that all three sons examined carried microdeletions in the Y chromosome, two of which were the same as those found in their fathers. The third microdeletion was similar to but longer than that of his father. These results support the view that Y chromomal microdeletions can be transmitted and expanded through ICSI.

Stuppia et al. (1996) have reported that widening of microdeletions transmitted via ICSI may account for the infertility of a son (Stuppia et al. 1996). If the severity of spermatogenic failure is related to the extent of microdeletions, ICSI may result in worsening of spermatogenic defects in the next generation. The mechanism of the widening of microdeletions is obscure. Lupski (1998) indicated that homologous locus-specific clusters of repetitive sequence elements caused loss of megabases of DNA (Lupski 1998).

Several researchers demonstrated that the retroviral sequence containing homologous repetitive sequences caused microdeletions in the AZFa region because the homologous repetitive sequences induced intrachromosomal recombination events easily (Kamp et al. 2000; Blanco et al. 2000). The Y chromosome itself is also polymorophic and has many repetitive sequences. Therefore, the occurrence of recombinations in the $\mathrm{Y}$ chromosome may be more frequent than is the case with the other chromosomes. The mechanism of widening the microdeletion via generation may be the same reason. On the other hand, Chang et al. (1999) have reported that a father of five children, including four sons, was found to be azoospermic with Y chromosomal microdeletions at the age of 63 years. All the sons were infertile with Y chromosomal microdeletions. These facts suggest that spermatogenic defects with Y chromosomal microdeletions may worsen with age.

Although the biological effect of the Y chromosomal microdeletions found in the three infants in this study will remain unknown until they reach adulthood, the possibility exists that the ICSI treatment may lead to an increase in the severity of spermatogenic defects and the number of infertile males in future generations. Therefore, before using ICSI in infertile couples with severe spermatogenic defects, the explanation and screening for microdeletions should be performed. Nap et al. (1999) demonstrated the role of genetic counseling in making the decision for treatment (Nap et al. 1999). According to their study, most infertile couples chose ICSI after taking genetic counseling. Nap et al. (1999) also indicated that the process of genetic counseling was important in making the final-decision. The rationale for ART is to provide infertile couples with an opportunity to have a healthy baby. It is therefore advisable for an infertile male contemplating ICSI because of severe spermatogenic defects to be examined for Y chromosomal microdeletions and, if any are found, to be provided with genetic counseling.

Acknowledgments This work is supported in part by a grant from the Promotion and Mutual Aid Corporation for private schools of Japan. The authors thank Dr. T. Tamaoki for help in preparing the manuscript and Miss Y. Nakata for excellent technical support. 


\section{References}

Blanco P, Shlumukova M, Sargent CA, Jobling MA, Affara N, Hurles ME (2000) Divergent outcomes of intrachromosomal recombination on the human Y chromosome: male infertility and recurrent polymorphism. J Med Genet 37:752-758

Chang PL, Sauer MV, Brown S (1999) Y chromosome microdeletion in a father and his four infertile sons. Hum Reprod 14:2689-2694

Foresta C, Moro E, Ferlin A (2001) Y chromosome microdeletions and alterations of spermatogenesis. Endocr Rev 22:226-239

Jiang M, Lien Y, Chen S, Ko T, Ho H, Yang Y (1999) Transmission of de novo mutations of the deleted in azoospermia genes from a severely oigozoospermic male to a son via intracytoplasmic sperm injection. Fertil Steril 71:1029-1032

Kamischke A, Gromoll J, Simoni M, Behre HM, Nieschlag E (1999) Transmission of a Y chromosomal deletion involving the deleted in azoospermia $(D A Z)$ and chromodomain $(C D Y 1)$ genes from father to son through intracytoplasmic sperm injection. Hum Reprod 14:2320-2322

Kamp C, Hirschmann P, Voss H, Huellen K, Vogt PH (2000) Two long homologous retroviral sequence blocks in proximal Yq11 cause AZFa microdeletions as a result of intrachromosomal recombination events. Hum Mol Genet 9:2563-2572

Kato H, Komori S, Nakata Y, Sakata K, Kanazawa R, Handa M, Kobayashi S, Koyama K, Isojima S (2001) Screening for deletions in interval D16-22 of the $\mathrm{Y}$ chromosome in azoospermic and oligozoospermic Japanese men. J Hum Genet 46:110-114

Kleiman SE, Bar-Shira B, Yogev L, Paz G, Yavetz H (2001) The prognostic role of the extent of Y microdeletion on spermatogenesis and maturity of Sertoli cells. Hum Reprod 16:399-402

Kobayashi K, Mizuno K, Hida A, Komaki R, Tomita K, Matsushita I, Namiki M, Iwamoto T, Tamura S, Minowada S, Nakahori Y, Nakagome Y (1994) PCR analysis of the Y chromosome long arm in azoospermic patients: evidence for a second locus required for spermatogenesis. Hum Mol Genet 3:1965-1967

Kostiner DR, Turek PJ, Reijo RA (1998) Male infertility: analysis of the marker and genes on the human Y chromosome. Hum Reprod 13:3032-3038

Kretser D, Baker H (1999) Infertility in men: recent advances and continuing controversies. J Clin Endocrinol Metab 84:3443-3450

Lupski JR (1998) Genomic disorders: structural features of the genome can lead to DNA rearrangements and human disease traits. Trends Genet 14:417-422

Ma K, Inglis JD, Sharkey A, Bickmore WA, Hill RE, Prosser EJ, Speed RM, Thomson EJ, Jobling M, Taylor K, Wolfe J, Cooke HJ, Hargreave TB, Chandley AC (1993) A Y chromosome gene family with RNA-binding protein homology: candidates for the azoospermia factor AZF controlling human spermatogenesis. Cell 75:12871295

McElreavey K, Krausz C (1999) Sex chromosome genetics '99. Am J Hum Genet 64:928-933

Nap AW, Van Golde RJT, Tuerlings HAM, De Sutter P, Pieters MHEC, Giltay JC, Kastrop PMM, Braat DDM, Kremer JAM (1999)
Reproductive decision of men with microdeletions of the $\mathrm{Y}$ chromosome: the role of genetic counseling. Hum Reprod 14:21662169

Page DC, Silber S, Brown LG (1999) Men with infertility caused by AZFc deletion can produce sons by intracytoplasmic sperm injection, but are likely to transmit the deletion and infertility. Hum Reprod 14:1722-1726

Palermo G, Joris H, Devroy P, Van Steirteghem AC (1992) Pregnancies after intracytoplasmic injection of single spermatozoon into an oocyte. Lancet 340:17-18

Pryor J, Kent-First M, Muallem A, Vna Bergen A, Nolten W, Roberts K (1997) Microdeletions in the Y chromosome of infertile men. N Engl J Med 336:534-539

Reijo R, Lee T-Y, Salo P, Alagappan R, Brown LG, Rosenberg M, Rosen S, Jaffe T, Straus D, Hovatta O, de la Chapelle A, Silber S, Page DC (1995) Diverse spermatogenic defects in humans caused by $\mathrm{Y}$ chromosome deletions encompassing a novel RNA-binding protein gene. Nature Genet 10:383-393

Simoni M (2001) Molecular diagnosis of Y chromosome microdeletions in europe: state-of-the-art and quality control. Hum Reprod 16:402-409

Simoni M, Carani C, Gromoll J, Meschede D, Dworniczak B, Behre HM, Rolf C, Horst J, Abshagen K, Nieschlag E, Kamischke A (1997) Screening for deletions of the $\mathrm{Y}$ chromosome involving the $D A Z$ (Deleted in AZoospermia) gene in azoospermia and severe oligozoospermia. Fertil Steril 67:542-547

Stouffs K, Lissens W, Van Landuyt L, Tournaye H, Van Steirteghem A, Liebaers I (2001) Characterization of the genomic organization, localization and expression of four PRY genes (PRY1, PRY2, PRY3 and PRY4). Mol Hum Reprod 7:603-610

Stuppia L, Calabrese G, Franchi PG, Mingarelli R, Gatta V, Palka G, Dallapiccola B (1996) Widening of a Y-chromosome interval-6 deletion transmitted from a father to his infertile son accounts for an oligozoospermia critical region distal to the $R B M 1$ and $D A Z$ genes. Am J Hum Genet 59:1393-1395

Thielemans B, Spiessens C, D'Hooghe T, Vanderschueren D, Legius E (1998) Genetic abnormalities and male infertility. A comprehensive review. Eur J Obstet Gynecol 81:217-225

Van Steirteghem AC, Nagy Z, Joris H (1993) High fertilization and implantation rates after intracytoplasmic sperm injection. Hum Reprod 8:1061-1066

Vogt PH (1998) Human chromosome deletions in Yq11, AZF candidate genes and male infertility: history and update. Mol Hum Reprod 4:739-744

Vogt PH, Edelmann A, Kirsch S, Henegariu O, Hirschmann P, Kiesewetter F, Kohn FM, Schill WB, Farah S, Ramos C, Hartmann M, Hartschuh W, Dschede D, Behre HM, Castel A, Nieschlag E, Weidner W, Grone H-J, Jung A, Engel W, Haidl G (1996) Human Y chromosome azoospermia factors (AZF) mapped to different subregions in Yq11. Hum Mol Genet 5:933-943

Vollrath D, Foote S, Hilton A, Brown LG, Beer-Romero P, Bogan JS, Page DC (1992) The human Y chromosome: a 43-internal map based on naturally occurring deletions. Science 258:52-59 